\title{
ÉLIDE, GILBERTO, IMAGISMO E LÍNGUA DE UNIVERSIDADE
}

\author{
Élide Rugai Bastos. As criaturas de Prometeu: Gilberto Freyre e a formação da socie- \\ dade brasileira. São Paulo, Global.
}

\section{Roberto Motta}

\section{Pensamento, imagem e universidade}

Gilberto Freyre jamais completou a tradução, ${ }^{1}$ em conceitos claros e distintos, em proposições articuladas, com seqüência e conseqüência, de sua muito poderosa intuição sobre o que faz o Brasil ser o Brasil. ${ }^{2} \mathrm{E}$, apressando os raciocínios, ouso dizer que há oposição diametral entre o modo gilbertiano de pensar e o paradigma de ciência social que veio a prevalecer na Universidade de São Paulo e que vem a difundir-se ou confundir-se com o paradigma de outras universidades, em São Paulo

Agradeço ao antropólogo Sílvio Soares da Silva pela paciência com que leu, comentou e contribuiu para melhorar, na forma e no conteúdo, a versão preliminar deste texto. Agradeço também a Ana Novais, da Universidade de São Paulo, por suas pertinentes sugestões, que foram muito levadas em conta pelo autor na preparação da versão final deste trabalho. e noutros estados. E é justamente a tradução de Gilberto Freyre em termos desse paradigma que Élide Rugai Bastos se propõe fazer em As criaturas de Prometeu: Gilberto Freyre e a formação da sociedade brasileira.

Em outros trabalhos (entre os quais Motta, 2000) referi-me ao contraste entre o muito cartesiano Florestan Fernandes, ${ }^{3}$ buscando operar por meio de conceitos bem ajustados, e a apreensão, na aparência mais artística do que cientifica, de Gilberto Freyre, para o qual a linha reta nunca é o menor caminho entre dois pontos. Ora, o exercício científico, ${ }^{4}$ inclusive no campo da sociologia, da antropologia e da história, deve necessariamente passar por essas duas etapas, isto é, pela intuição inicial, ainda que artística ou "metafísica", e por seu desdobramento em definições e teses capazes de serem testadas ou verificadas, direta ou indiretamente, próxima ou remotamente, através da observação 
empírica. ${ }^{5}$ Não se segue que cada pesquisador seja igualmente forte nos dois momentos. Haverá aqueles em que predominam as grandes intuições, como, para citar eminente exemplo internacional, é o caso de Max Weber, cuja tese sobre $A$ ética protestante e o espirito do capitalismo (mas Weber não se esgota nessa tese) jamais foi objeto de verificação plenamente convincente, nem mesmo de completa explicitação conceptual. ${ }^{6}$ Outros serão mais fortes nas definições e na escolha daquilo que, na velha e boa metodologia, se denominavam "indicadores". Pode, portanto, haver uma divisão do trabalho.

Os grandes livros de Gilberto $^{7}$ - e, entre estes, em primeiro lugar Casa-grande \& senzala - representam, para usar a expressão adotada por certo estudioso do sagrado, ${ }^{8}$ um mysterium tremendum et fascinosum. Percebe-se que está dizendo coisas muito importantes, muito abrangentes, muito ambiciosas, sobre a formação social e histórica do Brasil. E estas afirmações se exprimem em tom maior, com extraordinário vigor literário e, nos trabalhos decisivos, com a total segurança que faz que o leitor (para voltar a Roberto da Matta) imediatamente perceba com quem está falando, mesmo que não entenda imediatamente (apesar do estilo aparentemente muito claro) o que está sendo dito.?

A autora, com muita sagacidade, observa que

[...] o pensamento de Gilberto coloca-se como se o autor fosse fustigado e às instigações respondesse com teorias sobre teorias. Assim, não se pode compreendê-lo a partir de uma linha teórica única. Buscar em seu trabalho uma coerência conceitual e criticá-lo por não nos depararmos com ela é uma visão estéril (Bastos, 2006, p. 201).

Igualmente muito sagaz a passagem em que afirma ser

[...] provável que Gilberto Freyre se tenha recusado a ingressar na Universidade devido ao fato que nela não havia espaço para seu ecletismo. As controvérsias metodológicas e teóricas próprias dos ambientes universitários seriam incômodas para ele (Idem, p. 202).

Mas será que uma obra simplesmente eclética teria sido capaz de obter tanta repercussão e ocasionar tantos debates ou não teria sido, desde o princípio, rejeitada, com um simples gesto de desprezo, pelos comentadores? $\mathrm{Na}$ realidade, as declarações sobre o "ecletismo" da obra de Gilberto haverão de ser interpretadas à luz do que a própria autora diz logo na "Introdução" (pp. 11-16):

Não se trata de repetição e sim de invenções melódicas e
harmônicas que indicam a presença de uma obra plena de
organicidade. A genialidade desse desdobramento é ine-
gável! [...] O autor estabeleceu um conjunto [...]. Em
cada um [dos elementos desse conjunto] há a retomada,
em outra tonalidade, dos temas desenvolvidos desde o
primeiro texto. A articulação entre patriarcalismo, inter-
pretação de etnias/culturas e trópico constitui-se na uni-
dade explicativa do pensamento freyriano (Idem, p. 11).

Gilberto teria com toda certeza gostado muito dessa ouverture. Mais adiante a autora reafirma seu projeto:

Busquei compreender a arquitetura interna da obra freyriana, suas linhas mestras e articulações principais. Ainda, a estrutura teórica e o âmbito de suas interpretações. Também preocupei-me em desvendar os diálogos explícitos ou implícitos, que realiza com o pensamento brasileiro, aceitando ou rejeitando diferentes explicações sobre a formação nacional (Idem, p. 15).

Esconde-se, portanto, sob o ecletismo de Gilberto, conforme a própria Élide, um pensamento de exacerbada coerência. Tudo se deslinda ao puxarmos o fio da inspiração, ou das inspirações teóricas que atravessam a obra de Gilberto. Ainda que Élide Rugai Bastos tenha toda razão ao falar do "coquetismo" com que Gilberto Freyre "afirma ser e não ser sociólogo" (Idem, p. 200), nosso autor tinha mais razão do que ele próprio talvez acreditasse, ao querer definir-se acima de tudo como "escritor", ou ao reivindicar estilo "imagístico". ${ }^{10} \mathrm{Se}$ Gilberto, do princípio ao fim, não se afasta da coerência gerada por seus pontos de partida, é também verdade que os intuía, para falar agora como São Paulo, "em espelho, como em enigma". Tem, portanto, toda razão Élide ao destacar o incômodo que lhe causavam as controvérsias teóricas e metodológicas. Dizer que nosso autor tinha uma certa desconfiança dos conceitos claros e distintos e pouco apreço a teses consistentemente, sistematicamente articuladas, equivale a dizer, citando Hegel ${ }^{11}$, que o pensamento de Gilberto se parece ao "som de sinos e sobe como nuvens de perfume; é uma espécie de música que não atinge a forma concep- 
tual, que é o único modo objetivo de pensar" (Hegel, 1967, p. 257). ${ }^{12}$

E é em termos de música que Élide se aproxima de Gilberto, comparando a complexidade, mas também a unidade fundamental da sua obra à coerência temática de Beethoven. Mas não há, afinal, intuição nem imagem que ao menos virtualmente não se prolonguem em conceitos e proposições. Neste prolongamento encontra-se a grande realização do trabalho de Élide. Com seu livro completa-se um processo muito difícil, que é a recepção ou a tradução da obra de Gilberto Freyre em língua de universidade, em língua de ciência no sentido estrito da palavra, utilizando já não imagens, já não o brilho literário do escritor, mas os conceitos (e as teses ou hipóteses que os articulam), que, como já notado, representam o modo objetivo de pensar.

Mas não se trata apenas de um ensaio sobre a epistemologia freyriana. É também uma introdução de alto valor didático. Convém, portanto, que a sigamos pelos diversos capítulos, ainda que sem esgotá-los, o comentador detendo-se sobretudo nos temas mais ligados à sua própria reflexão. Depois de sucintas apresentações, que servem também para marcar a articulação fundamental (e musical) da temática dos principais livros de Gilberto - Casa-grande \& senzala, Sobrados e mucambos, Ordem e progresso, Nordeste -, a autora anuncia as grandes linhas, os leitmotiven, de sua interpretação da obra freyriana:

Influências individualistas estatistas e coletivistas se apresentam como desagregadoras do sistema patriarcal. Foi a família, a grande força permanente na formação nacional, influência conservadora e disseminadora dos valores patriarcais, a grande ameaçada. Mais ainda, ela conferiu unidade nacional ao país, pois a forma pela qual no Brasil tornou-se possível a convivência pacífica das culturas foi a existência e a permanência do patriarcalismo. Este se constituiu na garantia da interpenetração de valores sociais de caráter diversificado; através dele operou-se a síntese não conflituosa que impediu rupturas (Bastos, 2006, p. 13).

E logo depois a autora se refere à, segundo Gilberto,

[...] singularidade da decadência do patriarcado no Brasil. Diferentemente do que ocorreu em outros países, esta foi marcada pela acomodação, onde se alternam per- das e sobrevivências. A marca brasileira é a conciliação. $\mathrm{Na}$ mudança alteraram-se as formas e o acessório, mas o substantivo permaneceu. A transformação não se processou de modo linear, tem a conformação de um labirinto. Seu trabalho busca a reconstrução desses caminhos sinuosos (Idem, p. 14).

Voltaremos adiante a este tema, tanto mais que a própria Élide também retornará, antes do fim do livro, à questão do patriarcalismo e dos aspectos mais tradicionalistas ou conservadores do pensamento de Gilberto.

\section{Mito e história}

A maior parte do capítulo I, "O mito Gilberto Freyre" (pp. 18-37), consiste na apresentação de uma autobiografia, formada, como diz Élide, "de trechos selecionados da obra e de entrevistas com Gilberto Freyre" (Idem, p. 36). É “a imagem oficial de Gilberto Freyre que ele próprio, ao longo de muitos anos, teve o cuidado de administrar, de modo direto ou indireto" (Idem, p. 19). É a versão canônica do "mito". ${ }^{13}$ É a história do menino, considerado retardado, que domina o desenho, a imagem (tema recorrente), antes da palavra, e que aprende a ler e escrever primeiro em inglês do que em português. Depois de brilhantes estudos num colégio americano do Recife, segue para Baylor University, no Texas, com especial destaque para o Professor A. J. Armstrong, "mestre de Literatura Comparada". Dessa universidade provinciana, já com o grau de "bachelor", migra para a muito cosmopolita Universidade de Columbia na cidade de Nova Iorque, ${ }^{14}$ onde estuda "ciências políticas, jurídicas e sociais" e na qual, ao que afirma, "O Professor Franz Boas é a figura de mestre de que me ficou até hoje maior impressão" (Freyre, 2003, p. 31). É deste período a famosa visão, na "neve mole de Brooklin", dos marinheiros brasileiros, mulatos e cafuzos, que davam a impressão de serem "caricaturas de homens", mas isto porque eram "cafuzos e mulatos doentes". Tudo indica que se tratasse de tipos "cacogênicos", termo várias vezes usado na entrevista com que Élide encerra o volume (Bastos, 2006, pp. 207-220). Mas "cacogênicos" capazes, em poucas gerações, 
de transformarem-se em "eugênicos", o que Gilberto, à luz das teorias de Franz Boas, ${ }^{15}$ parece considerar como perfeitamente possível. ${ }^{16}$

\section{Tradição, invenção e verificação}

$\mathrm{Na}$ impossibilidade de tudo assinalar e comentar, destaco, do capítulo II, “Temas e personagens: a decadência” (pp. 38-56), um trecho fundamental:

Como falar em tradição num país tão novo como o Brasil, com um tão recente passado nacional? É [esta atitude] que explica o lusismo de Gilberto Freyre, presente de forma tão marcante em Casa-Grande \& Senzala. Inaugura-se, nessa obra, um processo de invenção de tradições, no sentido que Eric Hobsbawm confere ao termo. Essas tradições parecem pertencer à categoria dos termos "que estabelecem ou simbolizam a coesão social ou as condições de admissão de um grupo ou de comunidades reais ou artificiais". De certo modo é a fabulação sobre um período onde os conflitos ganham uma conotação épica. É a utopia de uma idade de ouro, onde a acomodação ocupa o lugar da luta, onde o dominado domina, de fato, aquele que se propõe como dominante. É por isso que o método eleito para a reconstrução da história é a empatia. Isso explica também o fato da história, em Gilberto, não ser datada. Ele próprio diz que os acontecimentos relatados ocorrem num transtempo. O que é claramente definido é o espaço: a casa-grande. O tempo é espacial. De certa forma é através do lusismo que Gilberto Freyre dialoga com os autores de sua época, influenciados pela Europa não lusitana, industrializada, portadora de idéias liberais. Por essa via, exorciza, de certa forma, o real presente: o Brasil a caminho da industrialização (Idem, p. 47).

Há muitas complexidades, nesta longa passagem, para que possam aqui ser todas discutidas. Mas uma coisa parece certa. Nesse lusismo, nessa tradição que se desdobra em região, encontra-se o que se pode considerar o núcleo duro da obra de Gilberto Freyre, a intuição da qual partem todas as outras, já sintetizando o tradicionalismo de Maurras com o relativismo cultural de Franz Boas. ${ }^{17}$

O capítulo III, “O ensaísmo dos anos 20” (pp. 59-79), é tão denso, do ponto de vista tanto da história como da sociologia das idéias, que me limitarei a uns poucos destaques. Uma longa seção tem por título “Que país é este?”. Nas palavras da autora:

Encontrei nesses ensaios, como pontos temáticos principais, dois elementos - a questão da cultura e a busca da identidade nacional - elementos estes que dão unidade. Em outros termos, os autores buscam resposta à indagação: afinal, que país é este? [...] Esses trabalhos assumem, no contexto em que são produzidos, um caráter imaginário, procuram "inventar" a cultura para legitimar a "invenção" da identidade nacional. O autor que conseguir articular estes dois elementos terá decifrado o dilema e dará o salto para uma nova etapa dos estudos sociais. Levanto a hipótese de que tal proeza será realizada por Gilberto Freyre (Idem, p. 61).

No mesmo sentido, encontramos mais adiante:

A partir dos novos critérios para a análise sociológica introduzidos por Gilberto Freyre na década de 1930, este processo tomará corpo de modo diverso, levará a outra direção as sugestões do ensaísmo dos anos $20 \mathrm{e}$ alterará a reflexão sobre o social. Casa-Grande \& Senz̧ala marca definitivamente a necessidade de assumirem-se os valores culturais em torno dos quais gira o social, os quais levam a sociedade brasileira a se distinguir das outras. É nesse ponto de inflexão que se coloca a obra freyriana (Idem, p. 71).

$\mathrm{E}$, finalmente, concluindo o mesmo capítulo, no fim da seção "A questão racial":

Gilberto Freyre [...] permite o equacionamento do problema em outro patamar. A raça vista como um 'problema', um obstáculo à integração, perde sua força. A redefinição do problema passará pela discussão do regionalismo e ao papel desempenhado pelo patriarcalismo na gênese e consolidação da sociedade brasileira (Idem, p. 76).

Creio que nesta passagem Élide quer dizer que no mercado concorrencial do ensaísmo da primeira metade do século XX, Gilberto Freyre apresenta o produto melhor acabado, resolvendo a equação composta destes três termos - "sociedade", "cultura" e "raça" -, os quais, juntos e tais como Gilberto os articula e Élide os explicita, resultam na "identidade nacional". ${ }^{18}$ Fico de pleno acordo, mas o que significam exatamente termos como "caráter imaginário", "inventar a cultura" ou "inventar a identidade nacional"? Estou persuadido de que os cientistas sociais inventam muita coisa. ${ }^{19}$ Roger Bastide, por exemplo, inventou muito sobre o Candomblé do Brasil, no sentido de que trouxe para esta religião componentes sobretudo associados à idéia de uma "metafísica africana", propostos por determinados autores e provavelmente já inventados por estes autores, componentes esses aos quais, no prin- 
cípio, nada ou virtualmente nada correspondia no próprio Candomblé. ${ }^{20}$

O exemplo de Bastide seria suficiente para que eu não ousasse contestar o autor, ou co-autor, de A invenção das tradições (Hobsbawm e Ranger, 1984). Entretanto, meus reflexos ${ }^{21}$ aristotélicos, popperianos e até leninistas ${ }^{22}$ se insurgem contra uma concepção que negue ao objeto da ciência, mesmo (e até sobretudo) da ciência social, da antropologia e da história ${ }^{23}$ a qualidade de realidade objetiva, existindo fora de nossa consciência de estudiosos. As teorias de Gilberto Freyre, uma vez que seus conceitos e hipóteses estejam devidamente explicitados (e este é justamente o empreendimento de Élide), deverão possuir referentes empíricos observáveis e delas deverá então ser possível deduzir hipóteses capazes de serem testadas ${ }^{24}$ pela observação empírica. $^{25}$

\section{Patriarcalismo e miscigenação}

O capítulo IV, “O Patriarcalismo” (pp. 81-111), parece mais próximo da temática de Sobrados e mucambos do que de Casa-grande \& senzala. Contém uma longa seção sobre "O processo de decadência". Passo a citar:

Freyre aponta três momentos de crise na história do patriarcalismo brasileiro: a invasão holandesa no século XVII, a vinda de D. João VI, em 1808; a abolição da escravatura e a proclamação da República, no final do século XIX (Idem, p. 89).

Em última análise, e

[...] mesmo sem que essa seja sua intenção, Gilberto Freyre, principalmente em Sobrados e Mucambos, cujo objeto é a análise da transição, descreve o processo de avanço do capitalismo, a conseqüente liberalização e o predomínio do público sobre o privado que o acompanha (Idem, p. 96).

A “pá de cal” no enterro do sistema [...] foi a mudança nas relações entre senhores/escravos. Estas se transformaram de relações pessoais a impessoais, graças à extensão dos empreendimentos agro-industriais, à substituição do engenho pela usina (Idem, p. 97$).{ }^{26}$
Porém "os tempos de consolidação e decadência se cruzam” (Bastos, 2005, p. 108). Lamentando o fato de que o espaço não permite que me detenha, como gostaria, nos detalhes deste capítulo, termino com uma citação final, que começa com Élide e termina com Gilberto:

Se o patriarcalismo, como forma social, tem certa rigidez, permite de outro lado flutuações de conteúdo e substância, ocorre um (Idem, p. 102) "amalgamento de raças e culturas, principal dissolvente de quanto houve de rígido nos limites impostos pelo sistema mais ou menos de relações entre os homens às situações não tanto de raça como de classe, de grupos ou de indivíduos. [...] Até o que havia de mais renitentemente aristocrático na organização patriarcal de família, de economia e de cultura foi atingido pelo que sempre houve de contagiosamente democrático ou democratizante e até anarquizante, no amalgamento de raças e culturas e, até certo ponto, de tipos regionais, dando-se uma espécie de despedaçamento das formas mais duras, ou menos plásticas, por excesso de trepidação de conteúdo" (Freyre, 1951, pp. 354-355, apud Bastos, 2006, p. 102).

Este último trecho nos reenvia ao núcleo duro do sistema gilbertiano, com incontestáveis marcas boasianas. Uma só citação basta, em comparação com o que acaba de ser transcrito, para demonstrar essa afinidade:

O amalgamento dos Negros pelos Maometanos é particularmente facilitado pela instituição da poligamia, os conquistadores casando com mulheres nativas e criando seus filhos como membros da própria família (Boas, 1974b, p. 226). ${ }^{27}$

O capítulo V, "Etnias e culturas” (pp. 112-141), trata, em sucessivas seções, do português, do indígena e do negro. É, para muitos efeitos, continuação do capítulo anterior, pois tudo gira em torno de miscigenação e esta, como já vimos, decorre do patriarcalismo. ${ }^{28}$ Vamos aos destaques. Primeiro ao texto de Gilberto:

"O segredo do sucesso do Brasil em construir uma civilização humana, predominantemente cristã e crescentemente moderna, na América tropical, vem da capacidade do brasileiro em transigir. Enquanto os ingleses, mais do que qualquer outro povo, possuem tal capacidade na esfera política - seu sistema político é magistral combinação de valores aparentemente antagônicos - os brasileiros vêm conseguindo ainda maiores triunfos, aplicando essa capacidade à esfera cultural e social, na maior amplitude. Daí sua relativa democracia étnica: a ampla, 
embora não perfeita, oportunidade dada no Brasil a todos os homens, independente de raça ou cor, para se afirmarem brasileiros plenos" (Freyre, 1971, pp. 4-5, apud Bastos, 2006, 114).

E agora passemos a Élide:

Segundo o autor, o processo de acomodação no campo cultural ao mesmo tempo requer e é produto do amálgama no biológico e étnico. Tal processo teria sido realizado, no Brasil, pela miscigenação: primeiramente dos portugueses e espanhóis com os árabes e judeus, posteriormente desses mestiços com os índios e negros. Por esse motivo as tensões na sociedade brasileira não se explicitam em conflitos que emergem em movimentos sociais. Por isso a história é pacífica: dá-se sem rupturas. Essa é a grande temática de Casa-Grande \&o Senzala (Bastos, 2006, p. 114).

Pergunto-me, finalmente, se da premissa, que, ao menos para argumentar, pode-se considerar como válida, da acomodação, do amálgama, da miscigenação "no biológico e étnico", possa-se, sem outra forma de processo, extrapolando do próprio "biológico e étnico", ${ }^{29}$ tirar a conclusão de que as tensões não se explicitam em conflitos sociais. Haveria, para a autora, uma história "pacífica e sem rupturas", e esta seria a grande temática de Casa-grande \& senzala, ${ }^{30}$ que é, como se pode ver pelo subtítulo, um estudo sobre a formação da familia brasileira sob o regime da economia patriarcal. Ora "patriarcalismo" é um instrumento de trabalho, com um alvo bem preciso no contexto de um livro bem datado. ${ }^{31}$ Não se trata de uma monografia altamente especializada, de um Herr Doktor de Heidelberg ou Tübingen, ${ }^{32}$ sobre o relacionamento entre determinado tipo de família e um sistema econômico bem delimitado. Gilberto quer falar da sociedade, da cultura, do espírito ${ }^{33}$ do país como um todo. Acrescente-se que a partir do conceito de patriarcalismo $^{34}$ em si mesmo considerado, não se pode deduzir muita coisa, salvo a explicitação dos componentes do próprio conceito. Além disso, pareceme que só com um generoso uso de hipóteses ad $h o c^{35}$ é que se possa concluir pelo caráter fundamentalmente conservador ou estático do conceito.

Passo rapidamente à seção "O português", destacando o seguinte trecho:

O povo é marcado por uma rusticidade constitutiva, produto da socialização resultante da passagem de uma sociedade não totalmente tradicional a uma sociedade não tipicamente moderna. É uma rusticidade que expressa uma recusa à Europa industrializada, marcada por uma falta de instrução adequada às novas formas de organização da sociedade (Idem, p. 117). ${ }^{36}$

Nesta e noutras passagens, Élide adentra-se numa das temáticas fundamentais da obra de Gilberto, que já se anuncia em Casa-grande e até mesmo antes. ${ }^{37}$ Trata-se da oposição entre tradição e modernidade. É o lado maurrasiano e mais tradicionalista de Gilberto, que convive, às vezes predominando, às vezes se subordinando, com seu lado mais boasiano e mais progressista. ${ }^{38}$ Essa oposição (da qual Élide está absolutamente consciente da primeira à última página do livro) se aguça, ou assume novas formas em dois contextos específicos. Primeiro, nos trabalhos originariamente escritos em inglês, que vieram a dar origem a Interpretação do Brasil (1947) e a Novo Mundo nos trópicos (1971), ${ }^{39}$ aos quais se podem acrescentar textos ocasionais como, por exemplo, "On the Iberian concept of time" (Freyre, 1963). Nestes trabalhos (não talvez sem enfatizar ou, às vezes, francamente exagerar características de ambos os lados), Gilberto ressalta o contraste entre o "tradicionalismo" brasileiro, luso-tropical ou hispano-tropical, de um lado, e, de outro, a civilização do Noroeste da Europa (Inglaterra, Alemanha, adjacências e prolongamentos ultramarinos), com ênfase no tratamento racionalizado do tempo, na produtividade e noutras características que já se exprimiam na belíssima passagem de Sobrados e mucambos, típica e arquetípica do imagismo de Gilberto Freyre:

A nova Europa impôs a um Brasil ainda liricamente rural, que cozinhava e trabalhava com lenha, o preto, o pardo, o cinzento, das civilizações "paleotécnicas" de que fala o Professor Mumford; o preto e o cinzento dos fogões de ferro, das cartolas, das botinas, das carruagens do século XIX europeu (Freyre, 1981b, p. 311).

A oposição se aguça nos trabalhos que publica entre 1955 e 1975, refletindo os grandes conflitos em que Gilberto se opôs, com todas as forças, aos projetos de desenvolvimento, alfabetização e conscientização, ${ }^{40}$ eminentemente representados, no Recife, pela Sudene de Celso Furtado; pelo Movimento de Cultura Popular, coordenado por uma plêiade de intelectuais e homens de ação, ligados ora à ortodoxia 
marxista, ora à ala progressista da Igreja; pelo Serviço de Extensão Cultural da Universidade Federal de Pernambuco, dirigido por Paulo Freire. Seus elogios ao analfabetismo se intensificam e se multiplicam. ${ }^{41}$

\section{Trópico, região e conciliação}

Chego ao capítulo VI “O trópico” (pp. 142165), do qual cito o primeiro e decisivo parágrafo:

O debate de Gilberto Freyre sobre o trópico, o qual denominará Tropicologia, pode parecer, à primeira vista, uma reflexão de menor importância no conjunto dos temas em questão na sua obra. Trata-se, porém, de estudo fundamental sobre o regionalismo e a tradição. É a ponta de lança da idéia de conciliação, que perpassa sua análise a respeito da formação nacional. Funda-se em dois princípios: de um lado, dialoga com os estudiosos da época que afirmam o determinismo do meio sobre a formação das personalidades individuais e das sociedades, de outro, indaga sobre a possibilidade de desenvolvimento, nas regiões tropicais, de formas avançadas de civilização (Bastos, 2006, p. 143).

Concordo em gênero, número e grau com a opinião de Élide. A Tropicologia ${ }^{42}$ é a continuação do regionalismo e do tradicionalismo com outros termos e métodos. Neste sentido - influenciada por Boas e Maurras, ora mais por um, ora mais por outro - a Tropicologia atravessa toda a obra de Gilberto de uma ponta a outra. Certamente já aparece na fase pré-boasiana de Gilberto, isto é, nesta beleza de ensaio que é Social life in Brazil in the middle of the nineteenth century (Freyre, 1922) e no Manifesto regionalista (Freyre, [1926] 1996), mas está também muito presente na fase máxima, que vai de Casagrande \& senzala (1933) até, a rigor, a segunda edição de Sobrados e mucambos (1951) e continua na obra do Gilberto tardio, de aproximadamente 1953 até o fim de sua atividade, que vem praticamente a coincidir com sua morte em $1987 .{ }^{43}$

Mas quero admitir que me sinto pouco confortável com a ênfase atribuída por Élide à "idéia de conciliação”. Sem dúvida, para Gilberto, existe conciliação no domínio das relações raciais, da cultura e da religião, como se vê na citação, por Élide, da passagem decisiva de Casa-Grande \& Senzala a respeito da:
"[...] política de assimilação, ao mesmo tempo que de contemporização seguida no Brasil pelo senhores de escravos. ${ }^{44}$ Consistiu principalmente em dar aos negros a oportunidade de conservarem, à sombra dos costumes europeus e dos ritos e doutrinas católicas, formas e acessórios da cultura e da mítica africana [...] o que dá bem idéia do processo de aproximação das duas culturas no Brasil" (Freyre, 1981a, pp. 355-356, apud Bastos, 2006, p. 134).

Não está, porém, escrito que da obra de Gilberto se possa concluir que essa aproximação se aplicasse a todos os domínios e a todos os períodos da história do Brasil, e isto inclusive porque, na medida em que possa ser considerado como pensador de Direita (na seqüência da influência maurrasiana), não é nada certo que tal pensamento seja sempre e sistematicamente a favor da conciliação. ${ }^{45}$

A temática do capítulo VII, "Variações de Prometeu" já foi em parte tratada neste comentário. Faço agora, ainda que muito de passagem, umas poucas observações. O aparecimento de Sociologia (Freyre, 1945) representa um mistério, pois este livro parece destoar do conjunto da obra freyriana, devido, como já se mencionou, à aversão de Gilberto pelos conceitos claros e distintos. Ora, Sociologia é um trabalho marcadamente "cartesiano", ${ }^{46}$ operando, e aqui uso a terminologia de Élide, à base de um pensamento que dissocia categorias, articulando-as porém à base de certos princípios, ou seja, que distingue primeiro para unir depois. Teria havido um manuscrito inicial remanejado por Gilberto em seu estilo inconfundível? E como se articula este livro com o conjunto da obra freyriana, em que reflete ou deixa de refletir a interpretação do Brasil presente nos principais livros do autor?

Não quero abandonar o capitulo sem fazer ainda duas observações, das quais sobretudo a primeira pode deixar-me em oposição não só a Élide, mas também a boa parte do pensamento social brasileiro. Não parece ser por si mesma evidente a afirmação de que "a descrição [do Brasil por Gilberto] vê as relações sociais do ponto de vista da classe dominante" (Bastos, 2006, p. 187). Não se tratando de uma proposição tautológica, tem de ser demonstrada através de "indicadores" precisos. Quais são as características desse ponto de vista? Como, onde e quando se encontram na obra de Gilberto? Em segundo lugar, ressalto que só com 
certas distinções eu poderia concordar que seja "temática privilegiada de Gilberto a transição ao moderno" (Idem, p. 181). ${ }^{47}$ Apesar dos gritantes subtítulos de Sobrados e mucambos - "Decadência do patriarcado rural no Brasil" (Freyre, 1951) - e de Ordem e progresso - "Processo de desintegração das sociedades patriarcal e semipatriarcal no Brasil sob o regime de trabalho livre: aspectos de um quase meio século de transição do trabalho escravo para o trabalho livre; e da Monarquia para a República" (Freyre, 1959) -, pareceria mais que a temática privilegiada residisse na persistência da tradição de uma identidade, ${ }^{48}$ a continuação daquilo que faz o Brasil ser o Brasil, numa perspectiva por assim dizer metahistórica, pois, como registrado pela própria Élide, "os acontecimentos relatados ocorrem num transtempo" (Bastos, 2006, p. 47).

O capítulo VIII, "Sou e não sou sociólogo" (pp. 196-206), foi de fato o primeiro a ser abordado neste comentário, a propósito do ecletismo de Gilberto. É curto, denso, provocante. Apesar de situado no final do livro, não parece implausível que reflita a camada talvez mais profunda da reflexão de Élide sobre Gilberto. Para a autora

O pensamento de Gilberto Freyre se constitui em um componente essencial do bloco de poder que se forma e desenvolve a partir de 1930. Em especial, legitima cientificamente o vasto segmento agrário e tradicionalista, sem deixar de indicar a necessidade de transformação do mesmo (Idem, p. 197).

Isto, entre outras coisas, ligado a que

O modo mais eficiente de obstaculizar tais intenções [de reforma agrária] seria demonstrar que a propriedade da terra tem desempenhado, no Brasil, papel equilibrador no seio da sociedade. No momento em que surge, 1933, Casa-Grande \& Senzala cumpre essa função. [...] O autor mostrará, no quadro que delineia, a não dissociação proprietário/propriedade. ${ }^{49}$ Esta associação apontaria óbices a um processo abrupto de reforma agrária, embora este ponto não esteja explícito na obra freyriana do período (Idem, p. 199).

O que aqui se deseja é que associações deste gênero fiquem explícitas, através de citações inequívocas de Gilberto ou de raciocínios cogentes por parte de Élide, que demonstrem a seqüência lógica entre Casa-grande \& senzala e a defesa da grande propriedade agrária.

\section{Gilberto na universidade}

A "Entrevista com Gilberto Freyre" (pp. 207220), já antes mencionada, poderia suscitar tratamento muito longo. Por isso passo diretamente às observações finais. Élide faz um belo trabalho de "tradução" do pensamento de Gilberto Freyre para a linguagem de universidade ou, se preferirmos, para a linguagem canônica das ciências sociais. $\mathrm{O}$ livro se articula de maneira coerente. Não se limita ao tratamento monográfico de algum subtema específico. Sem ser necessariamente exaustivo, sem precisar citar ou mencionar cada um de seus trabalhos, abrange, de maneira geral, a obra inteira do autor. Certamente vai ficar como um marco no longo processo de recepção - ou naturalização - de Gilberto Freyre pela universidade brasileira.

Faço, contudo, duas ressalvas. Primeiro, Élide o que ela em momento algum tenta esconder - é discípula de Florestan Fernandes e Octávio Ianni. Seu meio é, portanto, a Universidade de São Paulo e seus prolongamentos, como a Universidade de Campinas - Unicamp. Mas creio que se pode dizer que o modelo da USP - inclusive por causa do grande número de pesquisadores e docentes dos outros estados que vão fazer doutorado em São Paulo - tornou-se normativo para todo o Brasil. Note-se também que outros autores, brasileiros e estrangeiros, têm contribuído para essa "tradução". Mas Élide, que é professora do batente (se assim me posso exprimir), traz uma contribuição muito especial para que o pensamento de Gilberto Freyre seja aceito em aulas, conferências, debates, simpósios, o que, outra vez, não deixa de lembrar o processo weberiano de rotinização e institucionalizão do carisma. ${ }^{50}$

$\mathrm{O}$ processo tem seus riscos. O pensamento de Gilberto Freyre é baseado em intuições e imagens. Sua expressão é modulada de acordo com o gênero, o público e as circunstâncias históricas e políticas que variaram muito no decorrer de sua longa trajetória. As criaturas de Prometeu, conforme já salientado, inscreve-se dentro de um longo processo de "recepção". Ora, o que quer que se recebe, recebe-se segundo as especificidades de quem recebe. No processo, então, de tradução do pensamento de Gilberto em língua de universidade, - uni- 
versidade essa marcada pelo "cartesianismo" de Florestan Fernandes e Octávio Ianni - pode acontecer uma hiper-racionalização, uma "reificação" das intuições que se quer ajustar aos limites rigorosos dos conceitos. ${ }^{51}$

Mas não quero terminar sem um depoimento de ordem pessoal. Comentar o livro de Élide representou para mim um grande desafio. Fui forçado a rever muitas de minhas opiniões. Para melhor entender a interpretação de Élide, tive não só de reler seu livro muitas vezes, mas também muitos textos de Gilberto e muitos artigos de Franz Boas. Reconsiderei e reformulei opiniões anteriores. Aprendi muita coisa nova. Comecei um e terminei outro.

\section{Notas}

1 Adotando termos da sociologia da religião de Max Weber, digamos que Gilberto fosse um "carismático", com só imperfeita institucionalização sob a forma de um sistema teórico, isto é, de uma teoria socioantropológica, ou de um nítido compromisso institucional, apesar do Instituto, depois Fundação Joaquim Nabuco e do Seminário de Tropicologia.

2 Neste trecho, como em outros, o autor se reconhece devedor de Roberto da Matta (1996).

3 Florestan Fernandes e Octavio Ianni, de um modo ou de outro, estão muito presentes na reflexão de Élide, inclusive (mas não só) pelo uso recorrente dos conceitos de "burguesismo", "revolução burguesa" e assemelhados, como quando a autora diz que Gilberto "aponta para a inexistência de uma transição burguesa clássica” no Brasil (Bastos, 2006, p. 201).

4 Esta reflexão, com alguns ajustes terminológicos, em essência corresponde à "lógica da pesquisa científica" de Karl Popper (1975), embora possa também se valer de outros sistemas epistemológicos.

5 Portanto, em última análise, o que confere caráter científico a uma teoria não é nem a maneira como foi concebida nem mesmo a forma pela qual se expressa. $\mathrm{O}$ que importa, do ponto de vista estritamente científico, é que de uma teoria possam deduzir-se proposições empiricamente testáveis. Além disso, a Gilberto Freyre se aplica o que determinado comentador de língua alemã disse de Max Weber: "O critério com que Weber deve ser avaliado e que o especialista deve apli- car ao julgamento de suas investigações, não é o da exatidão nos detalhes, mas o da fecundidade de suas interrogações e interpretações" (Abramowski, 1966, p. 12).

6 Sobre este tema, ver Motta (2007).

7 É como "Gilberto", seguindo um velho hábito brasileiro e pernambucano, que Élide se refere muitas vezes ao autor que analisa, sem prejuízo de, noutras passagens, mencioná-lo como "Freyre", de maneira mais convencionalmente universitária. A Gilberto, segundo minhas recordações pessoais, teria agradado ser tratado como "Gilberto".

8 Trata-se de Rudolf Otto (1917).

9 Para continuarmos na antropologia, é a situação do pesquisador que, tendo passado um mês em certa tribo, achou que tinha entendido tudo, mas depois de um ano concluiu que não havia entendido nada. $\mathrm{Ou}$, ainda, do comentador que, tendo resolvido fazer a resenha de um livro, achou a princípio que com três dias de leitura já tinha entendido tudo. Mas, quando foi escrever, viu que, para captar as sutilezas do texto, precisava de pelo menos mais três meses.

10 Se entendida ao pé da letra, a expressão pareceria indicar um Gilberto menos "escritor" do que pintor ou desenhista, o que, como veremos adiante, se corroboraria por certos detalhes autobiográficos.

11 Em tradução livre.

12 Odilon Ribeiro Coutinho, falando também de Gilberto, pareceria ecoar Hegel ao escrever que "a imagem pura e a cadência musical são os dois signos característicos do Imagismo" (2005, p. 101).

13 A formação desse mito, com eventuais reformulações, merece estudo detalhado. Notemos que, apesar dos mais de 40 anos que Gilberto ainda viveria, seus rasgos fundamentais já se encontram no livro de Diogo de Mello Meneses (1944).

14 Cujo nome oficial é efetivamente Columbia University in the City of New York.

15 Jamais Gilberto Freyre esclareceu por que, na versão canônica de sua biografia, preferiu filiar-se a Franz Boas e à antropologia, e não à história, deixando ficar em silêncio que foi no Departamento de História de Columbia, sob a liderança de Carlton Hayes, que fez o curso de mestrado e defendeu a tese Social life in Brazil in the middle of the nineteenth century (Freyre, 1922), a qual, por si só, bastaria para assegurar ao autor lugar honroso na história do pensamento social brasileiro.

16 Logo depois de referir-se às "tendências semitas do português aventureiro para a mercancia e o tráfico" 
(Freyre, 2003, p. 34), Gilberto ressalta que "Spengler salienta que uma raça não se transporta de um continente a outro; seria preciso que com ela se transportasse o meio físico. E recorda a propósito os resultados dos estudos de Gould e de Baxter, e os de Boas, no sentido da uniformização da média de estatura, do tempo médio de desenvolvimento e até, possivelmente, a estrutura do corpo e da forma da cabeça a que tendem indivíduos de várias procedências reunidos sob as mesmas condições de 'meio físico'. De condições bioquímicas talvez mais do que físicas; as modificações por efeito possivelmente de meio, verificadas em descendentes de imigrantes - como nos Judeus, Sicilianos e Alemães estudados por Boas nos Estados Unidos - parecem resultar principalmente do que Wissler chama de influência do biochemical content [...] rápidas alterações parecendo resultar do iodo que contenha o ambiente. [...] E o sistema de alimentação teria uma importância considerável na diferenciação dos traços físicos e mentais dos descendentes de imigrantes" (Freyre, 2003, pp. 34-35). Sem nos aventurarmos aqui ao exame detalhado que merecem os estudos de Franz Boas no campo da Antropologia Física, notemos que não é nada certo que uma teoria da igualdade entre as raças possa consistentemente apoiar-se no pensamento deste autor. Convém, a esse respeito refletir sobre a seção "Racial capacity and cultural determinism”, em Boas (1974a, pp. 221-254). E, em seguida, apelemos para o que é quase um argumento de autoridade. Dificilmente poderíamos imaginar intérprete mais abalizado do pensamento de Boas do que seu discípulo Robert Lowie (por direito próprio, um dos maiores nomes da história da antropologia). Em seu livro The history of ethnological theory ele escreve a certa altura: "Examinemos agora as opiniões mais gerais de Boas. Em sua apreciação das raças tem sido correntemente citado como igualitário. Mas isto é um erro de leitores desatentos. Boas rejeita explicitamente o dogma de que não há diferenças entre a composição mental do Negro e de outras raças. [...] Ao contrário, se há qualquer significado na correlação entre estruturas anatômicas e funções fisiológicas, devemos admitir que existem diferenças" (Lowie, 1937, p. 136). É, portanto, com muito espírito de fineza que se há de interpretar o famoso trecho no qual, desde a primeira edição de Casa-grande \& senzala, em 1933, Gilberto afirma que "Foi o estudo de antropologia sob a orientação do Professor Boas que primeiro me revelou o negro e o mulato no seu justo valor - separados dos traços de raça os efeitos do ambiente ou da experiência cultural. Aprendi a considerar fundamental a diferen- ça entre raça e cultura; a discriminar entre os efeitos de relações puramente genéticas e os de influências sociais, de herança cultural e de meio. Neste critério de diferenciação fundamental entre raça e cultura assenta todo o plano desse ensaio" (Freyre, 2003, p. 32).

17 Diga-se de passagem, que efetivamente não faltam laivos de "lusismo", de "luso-tropicalismo", com democracia racial, influências islâmicas e tudo mais na obra de Franz Boas, dos quais sirvam de exemplo as seguintes passagens: "O sentimento de raça, entre Brancos, Negros e Índios no Brasil parece ser bem diferente do que é entre nós. [...] A discriminação entre essas três raças é muito menor e os obstáculos sociais para a mistura ou o progresso racial são muito menos marcados. [...] Talvez fosse exagerado dizer que nesses casos não existe consciência racial, mas esta é com certeza bem menos pronunciada do que no nosso caso" (Boas, 1962, p. 65). "O estudioso de relações raciais deve responder à questão sobre se, em sociedades nas quais os diferentes tipos raciais formam um grupo social homogêneo, desenvolve-se uma nítida consciência de raça. A questão não pode ser resolvida de forma categórica, mas as condições raciais no Brasil e o descaso pela raça no relacionamento entre Maometanos e infiéis mostra que a consciência da raça pode, na realidade, ser insignificante" (Boas, 1982, p. 15).

18 Esse trecho de Élide me faz pensar em Jorge Amado: "E então apareceu Casa-Grande \& Senzala. Saíamos do terreno da ficção, da pura criação literária, agora abria-se um novo caminho para o estudo, para a ciência. Foi uma explosão, um fato novo, alguma coisa como ainda não possuíamos e houve de imediato uma consciência de que crescêramos e estávamos mais capazes. Quem não viveu aquele tempo não pode realmente imaginar sua beleza. Como um deslumbramento. Assisti e participei desses acontecimentos, posso dar testemunho. O livro de Gilberto foi fundamental para toda a transformação sofrida no país, verdadeira alavanca. O abalo produzido na opinião pública por Casa-Grande \& Senzala foi decisivo. Uma época começava no Brasil, o aparecimento de tal livro foi decisivo" (Amado, 1962, pp. 30-31).

19 Sobre o tema específico de "Gilberto Freyre e a invenção do Brasil", ver também o muito pertinente ensaio de Roberto Cavalcanti de Albuquerque (2000).

20 O modelo por ele proposto (ver sobretudo em Bastide, 1958) veio a predominar entre os afro-brasilianistas e, direta ou indiretamente, afetou as representações que de sua própria religião fazem os filhos-de-santo. 
Em certo sentido (que não pode ser explicado neste contexto), contribuiu para sua decomposição, isto é, para sua "aculturação", termo que, para o próprio Bastide (principalmente no campo afro-brasileiro), podia ter sentido marcadamente pejorativo. Em nome da autenticidade africana, Bastide, embora nisto tivesse predecessores, acelerou o processo de corrosão da espontaneidade religiosa afro-brasileira (ver a este respeito Motta (1994, 2002b, 2004 e 2005).

21 Tudo isto em talvez pavoroso sincretismo.

22 O Lênin é o de Materialismo e empirocriticismo.

23 Isto não implica em recusar as diferenças de métodos e técnicas de pesquisa entre as ciências sociais e as ciências naturais.

24 Ou falseadas, dando-se ao termo o sentido que possui na obra de Popper em tradução brasileira (Popper, 1975). Todo o valor científico de qualquer proposição não tautológica reside nessa falseabilidade que acaba por muito aproximadamente significar o mesmo que testabilidade.

25 Esta é exatamente a mensagem que tento transmitir em meu artigo "Paradigmas de interpretação das relações raciais no Brasil" (Motta, 2000).

26 Tendo a ver nestas passagens laivos daquilo que denomino (Motta, 2000) a concepção de uma orto-história, de um único modelo válido ou possível de desenvolvimento, de tal modo que ao Brasil se aplicaria, como à Europa Ocidental, por meio dos mesmos processos e passando pelas mesmas etapas, a norma do avanço do capitalismo e da ascensão da burguesia. Apesar da inúmeras controvérsias em torno destas noções, não me deixo inteiramente convencer pelo pressuposto, talvez proveniente da sociologia do desenvolvimento de Talcott Parsons, de que o avanço do capitalismo implica em liberalização e, ao mesmo tempo, em predomínio do público sobre o privado.

27 Evidentemente não se tratava, nesta e noutras citações do mesmo antropólogo, de Gilberto Freyre olhando para os Negros no eito de algum engenho ou visitando um xangô do recifense bairro do Fundão, mas de Franz Boas contemplando a planície do Harlem "from the vantage point" (como se diz em inglês) de Mornigside Heights, área elevada na parte ocidental de Manhattan, onde fica situada a Universidade de Columbia.

28 A miscigenação, enquanto tal, resulta primariamente de determinados processos biológicos e certos condicionamentos demográficos. Já se disse que, na África, na Índia, no Brasil, no México, ou no que vieram a ser os Estados Unidos, o primeiro miscigenado nasceu nove meses depois da chegada do primeiro navegador, conquistador ou colonizador. Nas palavras de Rudiger Bilden, a miscigenação ocorre, "by necessity and habit" (1929, p. 72), em todas as partes do mundo e entre todas as etnias. Entretanto, no contexto deste comentário e, ouso pensar, do próprio livro de Élide (sem falar em Gilberto), é preciso ter em mente que se trata de uma forma particular de miscigenação, para cujo entendimento, além da biologia e da demografia, deve-se levar em conta determinado contexto cultural e determinados efeitos sociais. É a que prevalece no Brasil, noutras áreas da América Latina e por que não dizer? - no mundo islâmico. Entre esses efeitos sociais, ou mesmo entre eles predominantes, encontram-se, quaisquer que venham a ser as formas jurídicas que assumam e entendidas em sentido muito amplo, as características destacadas por Franz Boas, isto é, a poligamia, os conquistadores unindo-se às mulheres "nativas" (ou escravas) mais do que apenas en passant, e a criação dos filhos como membros da própria "família". Sobre cada um desses termos há muitos volumes de definições e controvérsias. Simplificando quase ao ponto do simplismo, digamos que nos Estados Unidos também houve miscigenação, ainda que, por motivos entre outros demográficos, menos intensa do que no Brasil. Uma diferença essencial consiste em que, pelo menos para o período anterior a Barack Obama, a prole não era educada como se pertencesse à própria família do "conquistador" ou "patriarca", com brilhante exceção dos descendentes da Índia Pocahontas, que se uniu em justas núpcias com o "conquistador" John Rolfe (1619) e, ao que consta, de certa escrava negra ou "quadrarona" do "patriarca" Thomas Jefferson (por volta de 1776) e talvez outras.

29 Terminologia bem mais de Élide do que de Gilberto.

30 Notemos que a citação que serve de apoio imediato à interpretação de Élide deriva de um livro que, como seu predecessor, Interpretação do Brasil (Freyre, 1947), foi escrito "para inglês ver" (se assim posso exprimirme), com inevitáveis adaptações, simplificações e estratégias de "captação de benevolência", que não se encontram necessariamente em Casa-grande \& senzala e sua órbita imediata.

31 Não sem medo de contradizer o que já afirmei, creio que se trata de uma espécie de "conceito operacional".

32 Ou do Engels de $A$ origem da família, da propriedade privada e do Estado. 
33 Ou do ethos, como ele talvez preferisse dizer.

34 Derivado da antropologia progressista de Franz Boas ou por ela fortemente influenciado.

35 E talvez extrapolando para o tempo de Casa-grande \& senzala posições políticas adotadas pelo autor noutras fases de sua movimentada carreira.

36 À passagem da autora segue-se imediatamente uma citação de Interpretação do Brasil: "A falta de instrução não quer necessariamente dizer ignorância; há, para compensá-la, um fundo de natural sabedoria, de imaginação e de humor que não deve ser desdenhado nunca" (Freyre, 1947, p. 69, apud Bastos, 2006, p. 117). Acredito, aliás, que tenha sido com um toque de humor que a autora tenha afirmado que "Trata-se, segundo Gilberto, de uma falta de instrução que se expressa pelo analfabetismo, que a rigor não representa um problema" (Bastos, 2006, p. 117). Esse mesmo senso de humor, indo, neste caso, bem além do texto e mesmo do espírito de Gilberto, encontra-se na seção "O negro": "Para contestar os racistas, afirma [...] que os negros aqui trazidos foram pretos de raça branca" (Idem, p. 129).

37 Ver, entre outros, o Manifesto regionalista que, em essência, parece remontar a 1926. Deste texto várias edições, destacando-se Freyre (1996).

38 Embora Maurras seja, muito a seu modo, progressista (não fosse ele declarado discípulo de Auguste Comte) e Boas, muito a seu modo, tradicionalista (não fosse ele tão simpatizante do sistema maometano de relações raciais).

39 O segundo sendo versão revista e aumentada do primeiro.

40 A esse respeito, ver Motta (2002a).

41 É num trabalho característico desse período que Gilberto se refere "[à]quele alemão de formação protestante [que] concluiu que o sistema português de educação e colonização era um fracasso desde que não instruía bem os nativos nas técnicas européias de ler e escrever. A esse preconceito de europeus de formação bíblica ou protestante, com relação ao que deva ser hoje, ou devesse ser desde que começou o contacto de europeus com não-europeus, a missão civilizadora dos europeus, venho chamando um preconceito "bíblico" (Freyre, 1961, p. 11). É no mesmo livro que fala de "analfabetos ou quase analfabetos uma atitude como que franciscana de confraternização com os indígenas, com os seus valores de cultura e com a natureza vegetal ou animal dos espaços quentes" (Freyre, 1961, pp. 246-247).
42 A biografia sobre Gilberto Freyre está cada vez mais extensa, no Brasil e no exterior. Contudo, não me consta haver estudo monográfico exaustivo sobre a Tropicologia do Gilberto, tal como a desenvolveu nas três ou quatro últimas décadas de sua vida. Os estudos tropicológicos institucionalizaram-se no Seminário de Tropicologia, primeiro na Universidade Federal de Pernambuco, onde, se Gilberto nunca quis ser professor ordinário, sempre desejou manter uma base, um pequeno campus avançado, sob seu comando ou de seus próximos auxiliares, entre os quais o antropólogo Sílvio Soares, autor de uma preciosa monografia sobre o Seminário (Soares da Silva, 2000), bem como o autor deste comentário. Havia, na reitoria da UFPE, uma pequena sala à disposição dos tropicologistas. Os membros do Seminário de Tropicologia reuniam-se, com pompa e circunstância, uma vez por mês durante o ano letivo. As coisas começaram a mudar quando a Fundação Joaquim Nabuco, em 1980, chamou para si o patrocínio do Seminário. Em 2003, o Seminário mudou-se, com armas e bagagens, para a Fundação Gilberto Freyre, onde continua a ser realizado sob a direção da antropóloga Fátima Quintas, autora e organizadora de muitos trabalhos sobre Gilberto Freyre, entre eles o muito recente Sexo à moda patriarcal: o feminino e o masculino em Gilberto Freyre (Quintas, 2008).

43 Porém nada há de rigoroso neste como noutros esboços de periodização. Pode-se também falar em distinções que não são apenas, ou não são primariamente cronológicas, mas antes influenciadas pelo gênero do trabalho e pelo público a que se quer dirigir, como em Interpretação do Brasil (Freyre, 1947) e outros trabalhos já aqui apontados.

44 Parece-me muito otimista, por parte de Gilberto, dar a entender, ou ao menos permitir que se conclua, que houvesse tal política de assimilação e contemporização propriamente dita. Tal política, no sentido amplo do termo, resultou da força das coisas nos planos demográfico, econômico, social, cultural, e - por que não? - religioso, e não de algum intelligent design ou projeto político deliberado e consciente.

45 Hesito também em seguir incondicionalmente a autora na seção "Tradição e modernidade" do mesmo capítulo. O Manifesto regionalista pertence à vertente maurasiana de Gilberto e, como tal, possui elementos tradicionalistas e só muito a seu modo modernistas. Mas não me parece, à primeira vista e sem outras explicações e distinções, que, para Gilberto, as pessoas "deixaram de reconhecer seu 'lugar social" e que "re- 
tomá-lo configura-se de fundamental importância para o equilíbrio nacional” (Bastos, 2006, pp. 154-155).

46 Apesar das aspas, não estou atribuindo a Élide o uso deste termo.

47 A passagem, porém, apresenta ambigüidade. Seria a temática privilegiada ou uma temática privilegiada?

48 Este último termo não é freqüente no vocabulário de Gilberto.

49 Eu relutaria muito em considerar Gilberto Freyre um precursor do movimento Família, Tradição e Propriedade, ativo no Brasil na segunda metade do século XX e talvez ainda hoje, embora não seja isso tampouco o que Élide está dizendo.

50 Com um germanismo paralelo a salonfähig (capaz de freqüentar os salões da alta sociedade), digamos que Élide faz com que Gilberto Freyre se torne universitätfähig.

51 Talvez isso seja ainda mais evidente em relação aos conceitos mais gerais, pois como se sabe, quanto mais ampla a extensão ou denotação de um conceito, mais limitada a sua compreensão ou conotação.

\section{BIBLIOGRAFIA}

ABRAMOWSKI, Günter. (1966), Die Geschichtsbild Max Webers: Universalgeschichte am Leitfaden des okzidentalen Rationalisierungsprozesses. Stuttgart, Erns Klett Verlag.

ALBUQUERQUE, Roberto Cavalcanti de. (2000), Gilberto Freyre e a invenção do Brasil. Rio de Janeiro, José Olympio.

AMADO, Jorge. (1962), "Casa-Grande \& Senzala e a revolução cultural", in Gilberto Amado et al., Gilberto Freyre, sua ciência, sua filosofia e sua arte, Rio de Janeiro, José Olympio, pp. 30-36.

BASTIDE, Roger. (1958), Le candomblé de Babia (Rite Nagô). La Haye, Mouton.

BASTOS, Élide Rugai. (2006), As criaturas de Prometeu: Gilberto Freyre e a formação da sociedade brasileira. São Paulo, Global.

BILDEN, Rudiger. (1929), "Brazil, laboratory of civilization”. The Nation, 128 (3315): 71-74, Nova York.

BOAS, Franz. ([1928] 1962), Anthropology and modern life. Nova York, Norton.

. (1974a), A Franz Boas reader: the shaping of American anthropology, 1883-1911. Chicago,
The University of Chicago Press (ed. George W. Stocking Jr.). (1974b [1894]), "Human faculty as determined by race", in - A Franz Boas reader: the shaping of American anthropology, 1883-1911. Chicago, The University of Chicago Press (ed. George W. Stocking Jr.), pp. 221-243. . (1982 [1931]), "Race and progress", in _. Race, language and culture, Chicago, The University of Chicago Press, pp. 3-17. COUTINHO, Odilon Ribeiro. (2005), "Imagismo, cor e cadência", in Gilberto Freyre on o ideário brasileiro, Rio de Janeiro, Topbooks, pp. 101-103.

FREYRE, Alfredo. (1970), Dos oito aos oitenta e tantos. Recife, Editora da Universidade Federal de Pernambuco [prefácio de Gilberto Freyre].

FREYRE, Gilberto. (1922), "Social life in Brazil in the middle of the nineteenth century". Hispanic American Historical Review, pp. 597-630, Durham, N.C.

(1945), Sociologia: introdução ao estudo de seus princípios. Rio de Janeiro, José Olympio.

. (1947), Interpretação do Brasil. Rio de Janeiro, José Olympio.

(1951), Sobrados e mucambos: decadência do patriarcado rural no Brasil. Rio de Janeiro, José Olympio.

(1959), Ordem e progresso: processo de desintegração das sociedades patriarcal e semipatriarcal no Brasil sob o regime de trabalho livre: Aspectos de um quase meio século de transição do trabalho escravo para o trabalho livre; e da Monarquia para a República. Rio de Janeiro, José Olympio.

. (1961), O Luso e o trópico. Lisboa, Comissão Executiva das Comemorações do $\mathrm{V}$ Centenário da Morte do Infante D. Henrique. . (1963), "On the Iberian concept of time”. The American Scholar, 32 (3), reproduzido em inglês em G. Freyre, O brasileiro entre os outros hispanos: afinidades, contrastes e possiveis futuros nas suas inter-relaçoes, Rio de Janeiro, José Olympio, 1975, pp. 132-144].

- (1964), Vida social no Brasil nos meados do século XIX. Trad. de Waldemar Valente. Recife, Instituto Joaquim Nabuco [2 ed. Rio de Janeiro, Artenova, 1977). 
. (1971), Novo mundo nos trópicos. Trad. de Olívio Montenegro e Luís de Miranda Correia. São Paulo, Editora Nacional/Edusp.

- (1975), O brasileiro entre os outros hispanos: afinidades, contrastes e possiveis futuros nas suas inter-relações. Rio de Janeiro, José Olympio.

- (1981a), Casa-grande \& senzala: formação da família brasileira sob o regime da economia patriarcal. 21 ed. Rio de Janeiro, José Olympio.

- (1981b), Sobrados e mucambos. 6 ed. Rio de Janeiro, José Olympio. . (1996), Manifesto regionalista. 7 ed.

Recife, Massangana [organização e apresentação de Fátima Quintas].

. (2003), Casa-grande \& senzala: formação da familia brasileira sob o regime da economia patriarcal. 47 ed. São Paulo, Global.

- (2006), Tempo morto e outros tempos: trechos de um diário de adolescência e primeira mocidade, 1915-1930. 2 ed. São Paulo, Global.

HEGEL, G. W. F. (1967), The phenomenology of mind. Trans. by J. B. Baillie. Nova York, Harper \& Row.

HOBSBAWM, Eric \& RANGER, Terence. (1984), A invenção das tradições. Rio de Janeiro, Paz e Terra.

LOWIE, Robert. (1937), The history of ethnological theory. Nova York, Rinehart.

MENESES, Diogo de Mello. (1944), Gilberto Freyre: notas biográficas. Rio de Janeiro, Casa do Estudante do Brasil [2 ed. Recife, Massangana, 1991).

MATTA, Roberto da. (1996), O que faz o Brasil Brasil. Rio de Janeiro, Rocco.

MOTTA, Roberto. (1994), "L'apport brésilien dans l'oeuvre de Bastide sur le candomblé de Bahia", in Philippe Laburthe-Tolra (sous la direction de), Roger Bastide ou le réjouissement de l'abîme, Paris, L'Harmattan, pp. 69-178.

. (2000), "Paradigmas de interpretação das relações raciais no Brasil". Estudos Afro-Asiáticos, 38: 113-134 (Universidade Cândido Mendes, Rio de Janeiro).

. (2002a), "A propósito de frades: Gilberto Freyre, Max Weber e o franciscanismo", in Elisalva Madruga Dantas e Jomard Muniz de Britto (orgs.), Interpenetrações do Brasil: encontros \& desencontros, João Pessoa, Editora da Universidade Federal da Paraíba, pp.87-92. . (2002b), "L'expansion et la réinventi- on des religions afro-brésiliennes: réenchantement et décomposition". Archives de Sciences Sociales des Religions, 117: 113-125.

. (2004), "Interpénétration des races, des religions et des idées: sur le prochain et le lointain, de Roger Bastide”. Ethnologie Française, tome xxxiv: 151-155.

(2005), "Memória, rito nagô e terreiros bantos: Roger Bastide e alguns de seus predecessores no Estudo do Candomblé", in Roberto Motta (org.), Roger Bastide hoje: raça, religião, saudade e literatura, Recife, Bagaço, 315-330. . (2007), "Weberianism, modernity, and the Fall of the Wall", in Laurence McFalls (ed.), Max Weber's 'objectivity' reconsidered, Toronto, Toronto University Press, 184-205.

O'T'TO, Rudolph. (1917), Das Heilige. Über das Irrationale in der Idee des Göttlichen und sein Verbältnis zum Rationalen. Breslau, Trewendt \& Granier.

POPPER, Karl. (1975), A lógica da pesquisa científica. Trad. de Leônidas Hegenberg e Octanny Silveira da Mota. São Paulo, Cultrix.

QUINTAS, Fátima. (2008), Sexo à moda patriarcal: o feminino e o masculino em Gilberto Freyre. São Paulo, Global.

SOARES DA SILVA, Sílvio. (2000), Um Seminário nos Trópicos: gênese e institucionalização da tropicologia em Pernambuco. Dissertação de mestrado em Antropologia, Recife, Universidade Federal de Pernambuco. 